\title{
The Impact of Information Technology on Industrial Automation - A Critical Evaluation
}

\author{
Joshy George ${ }^{1} \&$ S P Maj ${ }^{2}$ \\ ${ }^{1}$ Shell Prelude, Perth, Western Australia \\ ${ }^{2}$ Engineering Institute of Technology, Perth, Western Australia \\ Correspondence: S P Maj, Engineering Institute of Technology, 1031, Wellington St, West Perth, Western \\ Australia. Tel: 61-1300-138-522. E-mail: paulm@eit.edu.au
}

Received: October 10, 2017

Accepted: October 20, 2017

Online Published: January 30, 2018

doi:10.5539/mas.v12n2p142

URL: https://doi.org/10.5539/mas.v12n2p142

\begin{abstract}
Information Technology (IT) now impacts on all aspects of modern society (personal, commercial and industrial). The advances in IT may broadly be categorized into the following subsets of technologies: integrated circuits, communications, software engineering and Graphical User Interfaces. In the context of Industrial Automation (IA) it can be seen that some communication protocols, for example Modbus which was first introduced in the 1970's, has under gone numerous updates driven by IT developments with associated considerable improvements in performance and capability. By contrast some, for example HART which was first introduced in the 1980's, whilst it has undergone revisions it does not fully utilize the capabilities that IT can provide. For higher level IA systems they can be divided into four generations which can each be associated with specific IT developments. The first generation IA system is based on simple Proportional, Integral and Derivative (PID) controllers and ruggedized microprocessor based Programmable Logic Controllers (PLC). IA systems expanded in both complexity and scope through these generations to include Distributed Control Systems (DCS's) and Supervisory Control and Data Acquisition (SCADA). The fifth generation of IA systems may be associated with IT developments both on and over the horizon that include: Cloud Computing, Cyber Security and Internet of Things. Responses to these technologies include: General Electric (GE) Predix and Siemens MindSphere. Regardless of how IA is categorized there can be no doubt that IT is responsible for major technical developments - a process that is likely to continue.
\end{abstract}

Keywords: industrial automation, predix, MindSphere

\section{Introduction}

\subsection{Developments in Information Technology - A Perspective}

Information Technology has undergone rapid advances with ever increasing capabilities - the pace of which is likely to accelerate. To best understand these developments, IT may be categorized into the following subsets: integrated circuits, communications, software engineering and Graphical User Interfaces. In the case of integrated circuits this technology is only possible due to the invention of the solid state transistor in 1947. These discrete components were individually mounted on a printed circuit board. In the 1950's multiple transistors were fabricated on a single piece of silicon i.e. an integrated circuit. Levels of integration rapidly evolved from Small Scale, Medium Scale, Large Scale and Very Large Scale Integration (VLSI) - the basis of microprocessors, memory and control circuits. With each VLSI generation there were significant improvements in computational power. This computational power was the platform for the developments in Software Engineering. For the purposes of this paper Software Engineering can be considered to consist of the following sub-disciplines: programming languages, client server technologies, databases, search engines and Graphical User Interfaces (GUI's). GUI technology is taken to include not only rich, graphical interfaces but also the dynamic linking of information by hypertext. The most significant development in communication technology was the development in 1983 of the Open Systems Interconnect (OSI) conceptual model. There are two important points here. Firstly prior to this all communication systems were vendor based e.g. the Digital Equipment Corporation DECnet released in 1975. There were other proprietary standards with the resultant problem of interoperability between heterogeneous, vendor based standards and systems. The OSI, as the name implies, was an open standard to ensure interoperability. Secondly the 7 layer OSI model is only a conceptual model. The Transmission Control 
Protocol/Internet Protocol (TCP/IP) was developed in the early 1970's prior to the OSI model. However by the 1980 's TCP/IP was widely and universally accepted as the first practical implementation of the OSI model. Significantly these developments in IT are convergent. This can be illustrated by the development of GUI technologies. In the early Personal Computers (PC's) the user interface was only text (green) on a black background. Increases in computational power allowed the introduction of pull down menu's then colours and finally rich user interfaces. Significantly these interfaces include the use of hypertext thereby linking information on a user's screen on a global basis via TCP/IP. Developments in IT both on and over the horizon include: Cloud Computing, Cyber Security and Internet of Things (IoT). It is problematic to determine exactly when a new IT development transitions from over the horizon to on the horizon. For example, IOT was first developed about a decade ago but only now is its deployment becoming a reality. The question is 'how have developments affected Industrial Automation systems?' and what is likely to occur next?

\section{Method}

IA has been divided into two main sections - IA protocols and IA systems. Each of these was then analyzed in detail to determine how developments in IT have driven changes in IA.

\section{Results}

\subsection{IA Protocols}

Thirty different IA were analyzed with respect to year of introduction and, as a first crude benchmark the maximum speed (Table 1).

Table 1. Industrial Automation Protocols

\begin{tabular}{llll}
\hline Protocol & Developer & First Introduced & Maximum Speed \\
\hline Industrial Ethernet & Xerox & 1976 & $10 \mathrm{Gbps}$ \\
Modbus & Modicon & 1970 & $38 \mathrm{Kbps}$ \\
Modbus TCP/IP & Modicon & 1999 & $100 \mathrm{Mbps}$ \\
Modbus RTU & Modicon & 1979 & $19.2 \mathrm{Kbps}$ \\
Modbus Plus & Modicon & 1991 & $57.6 \mathrm{Kbps}$ \\
HART & Emerson & 1986 & $1.2 \mathrm{Kbps}$ \\
SDS & Honeywell & 1994 & $1 \mathrm{Mbps}$ \\
Fieldbus & Fieldbus Foundation & 1995 & $100 \mathrm{Mbps}$ \\
CAN Open & CAN Automation & 1993 & $20 \mathrm{Kbps}$ \\
AS-i & Factory Automation Suppliers, Germany & 1994 & 167.5 \\
BSAP & Bristol Babcock & - & $250 \mathrm{Kbps}$ \\
CC Link & Mistubishi Electric & 1997 & $1 \mathrm{Gbps}$ \\
CIP & ODVA & 1992 & - \\
EtherCAT & Beckoff & 2015 & - \\
EGD & GE Fanuc & 1998 & - \\
Ethernet/IP & Rockwell Automation & 2001 & - \\
HostLink & Omron & - & $9600 \mathrm{Bps}$ \\
Optomux & Opto22 & 1982 & $38.4 \mathrm{Kbps}$ \\
Pie-P & - & - & - \\
Profibus & Profibus International & 1989 & $500 \mathrm{Kbps}$ \\
Profinet IO & Profibus International & - & - \\
Rapienet & LSIS & - & $100 \mathrm{Mbps} \mathrm{to} \mathrm{1} \mathrm{Gbps}$ \\
SERCOS III & Sercos International & 2003 & $100 \mathrm{Mbps}$ \\
SERCOS Interface & VDW/ZVEI & 1987 & - \\
GE-SRTP & GE Fanuc & - & - \\
MPI & Seimens & 1991 & - \\
ControlNet & Rockwell Automation & 1997 & $5 \mathrm{Mbps}$ \\
DF-I & Rockwell Automation & - & - \\
DeviceNet & Rockwell Automation & 1994 & $500 \mathrm{Kbps}$ \\
DirectNet & Koyo & 1999 & $38.4 \mathrm{Kbps}$ \\
\hline & & &
\end{tabular}

IA protocols were then analyzed in the context of developments based on the 7 layer OSI model (and where 
appropriate the TCP/IP implementation (table 2). It can be seen that some IA protocols have developed over time with significant improvements in bandwidth from initial speeds of kbps to Gbps. By contrast some protocols, though there have been revisions no significant developments were found. For example, HART was initially capable of $1.2 \mathrm{kps}$ and even with revision 7 in 2007 this bandwidth remains the same. That is not to say HART is of no use, rather it is a technology with advantages and disadvantages and employed accordingly. Also HART revisions added more features to the first version. The changes like long tag identification and wireless HART were implemented in each revision.

To illustrate the underlying IT developments, it is instructive to consider Ethernet (and Industrial Ethernet) and Modbus. Ethernet. The Ethernet communications protocol initially was based on co-axial cable capable of 1 Mbps in half duplex mode employing the Carrier Sense Multiple Access/Collision Detection (CSMA/CD) protocol. This rapidly evolved to Unshielded Twisted Pair (UTP) cabling with connectivity via a Switch thereby allowing virtual point to point full duplex running at $200 \mathrm{Mbps}$ thereby replacing the inefficient CSMA/CD protocol. The use of an intelligent switch provided a higher level of network management that included Virtual Private Networks and Security protocols. UTP cabling has been superseded by fiber optic with the advantages of immunity to electromagnetic interference; long spans between nodes and, in the case of single mode fiber, in excess of 10Gbps. The Modbus protocol was introduce in 1970 with a bandwidth of 32kbps. This protocol progressively evolved to Modbus TCP/IP with Gbps capability.

Table 2. Developments of Industrial Automation Protocols

\begin{tabular}{|c|c|c|c|c|c|}
\hline Protocol & Introduced & OSI layer 1 & OSI layer 2 & OSI $3,4,5,6$ & OSI 7 \\
\hline $\begin{array}{l}\text { Industrial } \\
\text { Ethernet }\end{array}$ & 1976 & $\begin{array}{lr}\text { Coaxial } & \text { cable } \\
\text { CSMA/CD } & \text { i.e. } \\
\text { half duplex } & \\
1 \mathrm{Mbps} & \end{array}$ & No implementation & $\begin{array}{l}\text { No } \\
\text { Implementation }\end{array}$ & \\
\hline Modbus & 1970 & $\begin{array}{l}\text { RS485 } \\
38 \mathrm{Kbps}\end{array}$ & $\begin{array}{l}\text { MODBUS serial line } \\
\text { protocol (vendor } \\
\text { based) }\end{array}$ & No implementation & $\begin{array}{l}\text { Modbus Application } \\
\text { layer }\end{array}$ \\
\hline HART & 1986 & $\begin{array}{l}\text { Bell } 202 \\
1.2 \mathrm{Kbps}\end{array}$ & Hart Protocol & No Implementation & HART \\
\hline Fieldbus & 1995 & Physical layer & Data Link layer & & $\begin{array}{l}\text { FAS Sub- layer } \\
\text { FMS Sub-Layer }\end{array}$ \\
\hline CAN Open & 1993 & $\begin{array}{l}\text { CAN physical } \\
\text { layer } \quad \text { (ISO } \\
11898: 2003)\end{array}$ & $\begin{array}{l}\text { CAN data link layer } \\
\text { (ISO 11898:2003) }\end{array}$ & $\begin{array}{l}\text { CANopen application layer and } \\
\text { communication profile and } \\
\text { CANopen framework }\end{array}$ & Application \\
\hline AS-i & 1994 & $\begin{array}{l}\text { Physical: Cable, } \\
\text { power supply, } \\
\text { data decoupling, } \\
\text { APM }\end{array}$ & $\begin{array}{l}\text { Data Link: Data } \\
\text { telegram, start and } \\
\text { end bit, parity, error } \\
\text { handling }\end{array}$ & - & $\begin{array}{l}\text { Application: Message, } \\
\text { cycle, profiles, } \\
\text { automatic addressing }\end{array}$ \\
\hline BSAP & - & $\begin{array}{l}\text { RS232, RS422, } \\
\text { RS423, or RS485 }\end{array}$ & Link control & $\begin{array}{l}\text { Network control Transport } \\
\text { end-to-end }\end{array}$ & \\
\hline CIP & 1992 & IEEE 802.3 & IEEE 802.3 & $\begin{array}{l}\text { IP } \\
\text { TCP/UDP }\end{array}$ & CIP \\
\hline EtherCAT & 2015 & $\begin{array}{l}\text { Ethercat Ethernet } \\
\text { physical layer }\end{array}$ & Ethercat MAC & $\begin{array}{l}\text { IP(Layer 3) } \\
\text { TCP/UDP(Layer 4) }\end{array}$ & Standard data/ Real data \\
\hline CC Link & 1997 & IEEE $802.3 z$ & IEEE 802.3 & $\begin{array}{l}\text { Transient transmission/Cyclic } \\
\text { transmission }\end{array}$ & $\begin{array}{l}\text { Common object Access/ } \\
\text { Network oriented } \\
\text { common memory }\end{array}$ \\
\hline Profibus & 1989 & $\begin{array}{ll}\text { RS484, } & \text { Fibre } \\
\text { Optic, MBP } & \\
\end{array}$ & FDL & & $\begin{array}{ll}\text { FMS } & \text { DP-V0/ } \\
\text { DP-V1/DP-V2 } & \\
\end{array}$ \\
\hline Profinet IO & & $\begin{array}{l}\text { Standard Fast } \\
\text { Ethernet } \\
\text { IEEE 802.3- }\end{array}$ & Fast Ethernet & Profinet Realtime Channel & $\begin{array}{l}\text { Profinet Application } \\
\text { Layer }\end{array}$ \\
\hline Rapienet & - & Ethernet & Rapienet MAC & & HTTP/FTP \\
\hline Ethernet/IP & 2001 & Ethernet Physical & Ethernet & $\operatorname{IP}(3)$ & CIP Application layer \\
\hline
\end{tabular}




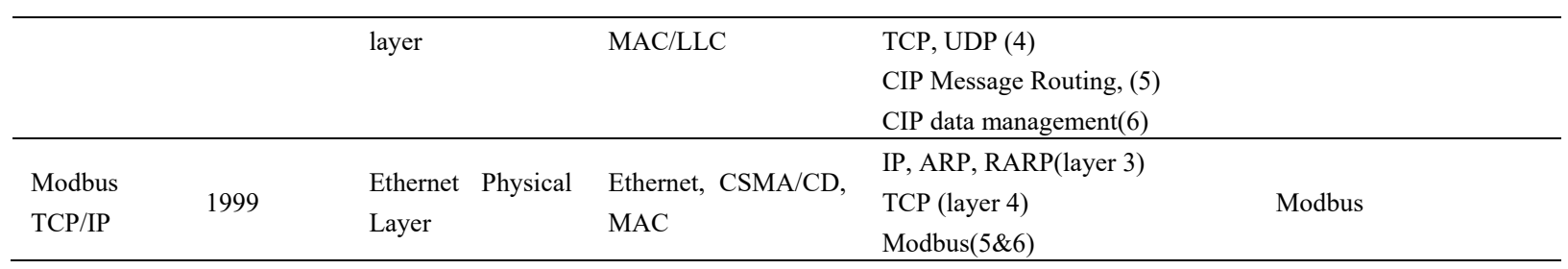

To illustrate the underlying IT developments, it is instructive to consider Ethernet (and Industrial Ethernet) and Modbus. Ethernet. The Ethernet communications protocol initially was based on co-axial cable capable of 1 Mbps in half duplex mode employing the Carrier Sense Multiple Access/Collision Detection (CSMA/CD) protocol. This rapidly evolved to Unshielded Twisted Pair (UTP) cabling with connectivity via a Switch thereby allowing virtual point to point full duplex running at 200Mbps thereby replacing the inefficient CSMA/CD protocol. The use of an intelligent switch provided a higher level of network management that included Virtual Private Networks and Security protocols. UTP cabling has been superseded by fiber optic with the advantages of immunity to electromagnetic interference; long spans between nodes and, in the case of single mode fiber, in excess of $10 \mathrm{Gbps}$. The Modbus protocol was introduced in 1970 with a bandwidth of $32 \mathrm{kbps}$. This protocol progressively evolved to Modbus TCP/IP with Gbps capability.

\subsection{IA Systems}

An IA system is considered as a portfolio of devices to achieve some form of process control. It is possible to categorize IA systems into generations based on IT developments available at that time (table 3). At the time of the first generation low cost microprocessors were available. A microprocessor is a generic device that is made application specific by programming. In effect a microprocessor can be programmed to act as a control device, use a spreadsheet or database etc. Hence the economies of scale drove unit cost down. First generation IA systems were based on simple Proportional, Integral and Derivative (PID) controllers and ruggedized microprocessor based Programmable Logic Controllers (PLC) using simple ladder logic as the programming language. However, these were largely discrete controllers. IA systems expanded in both complexity and scope through these generations to include Distributed Control Systems (DCS's) and Supervisory Control and Data Acquisition (SCADA). A DCS has a centralized supervisory control with associated distributed but integrated autonomous controllers allowing for remote monitoring and supervision available because of advance in IT. The IT developments outlined above were the basis of SCADA that employs remote controllers, networked communications, ability to make controller set point changes etc. SCADA itself has been characterized by generational developments variously referred to as standalone or monolithic with no networking to distributed with rudimentary networking but substantial vendor based; to networked based on the OSI model.

\subsection{IA Systems - Next Generation}

The fifth generation of IA systems may be associated with IT developments both on and over the horizon that include: Cloud Computing, Cyber Security and Internet of Things (table 3). This list is by no means complete. The use of Open Systems and wide spread interconnectivity has resulted in cyber-attacks on industrial systems (Anon., n.d.), (Anon., n.d.), (Anon., n.d.) (PREDIX GE, n.d.), (Anon., 2017), (Emerson Process Management -, n.d.). Early computers were mainframes with the end user having a keyboard and screen (a thin client) - all computation and storage was resident in the mainframe. The PC gave all computation and storage to the end user but with no means of communication between devices. IT developments led to Local Area Networking (LANs) and Wide Area Networking (WANs) based on TCP/IP with increasing performance. This allowed computation and storage to be resident in networked (meshed) devices resident in the 'cloud' and hence back to low cost thin clients for the end user. However, the main consideration here is the IT developments are of necessity convergent. Responses to these IT technologies include: General Electric (GE) Predix and Siemens MindSphere. Predix is a cloud based open system or platform in which end users can develop their own apps as the basis of a wide range of industries that include not only IA but also aviation, asset management etc. In effect Predix provides a platform that houses development tools and methodologies. The Predix cloud is defined as a layered architecture consisting of: data infrastructure, cloud foundry and services that include assets, analytics, data, security and operations. MindSphere is also a cloud based system that is also a development platform with secure communications. MindSphere consists of Edge Services (Asset management, edge communications and edge management) that interact with Edge device i.e. modular edge rung time interfacing with Edge apps. Regardless of how IA is categorized there can be no doubt that IT is responsible for major technical developments - a process that is likely to continue (Yokogawa Electric Corporation, n.d.), (Anon., 2017). 
Table 3. Generations of IA systems

\begin{tabular}{|c|c|c|}
\hline Generation & Advantages & Disadvantages \\
\hline $\begin{array}{l}\text { First } \\
\text { (PLC) }\end{array}$ & $\begin{array}{l}\text { Simple Logic Programming and Connection } \\
\text { methods } \\
\text { One-to-One communication }\end{array}$ & $\begin{array}{l}\text { No expansion provisions } \\
\text { No universal } \mathrm{I} / \mathrm{O} \text { - either analogue or digital } \\
\text { No safety features included }\end{array}$ \\
\hline $\begin{array}{l}\text { Second } \\
\text { (DCS\&SCADA) }\end{array}$ & $\begin{array}{l}\text { More expanding possibilities than first generation } \\
\text { Human Machine Interface(HMI) concepts } \\
\text { Universal I/Os } \\
\text { Compact Hardware }\end{array}$ & $\begin{array}{l}\text { Common platform for all types loops like fire } \\
\text { and gas, process, analytical, or different types } \\
\text { of plants etc. } \\
\text { Third party software add-ons are limited }\end{array}$ \\
\hline $\begin{array}{l}\text { Third } \\
\text { (Factorytalkbatch, RefineryWise \& } \\
\text { Sequence Manager) }\end{array}$ & $\begin{array}{l}\text { Moved close to software than hardware. } \\
\text { Dedicated software for critical applications } \\
\text { Safety concepts became as prime focus } \\
\text { Advanced communication methods established }\end{array}$ & $\begin{array}{l}\text { Upgrades are costly } \\
\text { Many software in the market for similar } \\
\text { applications, difficulty in selection } \\
\text { No access or control in sensors and actual } \\
\text { physical instruments. } \\
\text { No remote calibrations concepts }\end{array}$ \\
\hline $\begin{array}{l}\text { Forth } \\
\text { (FDM, PRM \& AMS) }\end{array}$ & $\begin{array}{l}\text { Remote Calibration facility } \\
\text { Interface between system and device } \\
\text { Adaptability of different protocols } \\
\text { Big freedom for add-on software }\end{array}$ & $\begin{array}{l}\text { Customisation is limited } \\
\text { Very costly upgrades/updates } \\
\text { Unauthorised operations are costly }\end{array}$ \\
\hline $\begin{array}{l}\text { Next } \\
\text { (Predix \& MindSphere) }\end{array}$ & $\begin{array}{l}\text { Open platform } \\
\text { Software oriented developments } \\
\text { Versatile for any application }\end{array}$ & $\begin{array}{l}\text { Cannot be defined as a single system } \\
\text { Costly } \\
\text { Developers required. Not a ready to go } \\
\text { programs. }\end{array}$ \\
\hline
\end{tabular}

\section{Discussion}

This paper has outlined the developments in Information Technology and categorized them to assist with their analysis - integrated circuits, communications, software engineering and user interfaces. Significantly each subset has had a convergent and mutual amplification effect on each other. Increasing levels of integration led to developments in software engineering and more advanced user interfaces - all of which needed great levels of computational ability. Arguably key points were the development of the microprocessor as a generic device that could be made application specific by means of software along with the universal acceptance of the OSI based TCP/IP communication stack. Being open had the effect of driving down development and device costs. All these impacted on IA. Within IA there are many different communication protocols an analysis of which has shown that some evolved over time to encompass IT developments whereas others remained technically relatively static. In the case of IA systems this paper shows how the generations are reflective of the developments in IT. IT developments have been referred to as over the horizon and on the horizon. However, it is difficult to determine which technology moves from over to on the horizon. For example, the Internet of Things which was first introduced about a decade ago was at one point on the horizon but failed at that time to be widely accepted and deployed. However, a number of IT developments are clearly on the horizon and include: Cyber security, cloud computing and Internet of Things. IA systems have responded to these advances with similar but competing systems and platforms (American Psychological Association, 1972).

\section{References}

American Psychological Association. (1972). Ethical standards ofm psychologists.

APG, H., n.d. A CAN OPEN USER GUIDE. s.l.:s.n.

Automation, R. T., n.d. Real Time Automation, “An Overview of EtherNet/IP”. s.1.s.n.

Blaise Barney, L. L. N. L., n.d. Message Passing Interface. s.l.:s.n.

Carlos Rojas, P. M., n.d. , "Guidelines for Industrial Ethernet Infrastructure Implementation:. A Control Engineer's Guide".

Lin, Z. H., \& Stephanie, P. (2013). An inside look at industrial Ethernet communication protocols. Retrieved from http://www.ti.com/lit/wp/spry254/spry254.pdf

MindSphere in action - Our open IoT operating system, MARCH. (2017). Retrieved from https://www.siemens.com/investor/pool/en/investor_relations/financial_publications/speeches_and_presenta 
tions/innodayusa/06_InnoDayUSA_MindSphere_20170327.pdf

Plant Resource Manager (PRM) (2017). Retrieved from https://www.yokogawa.com/in/solutions/products-platforms/solution-based-software/asset-management-soft ware/field-device-management-prm/

Yokogawa Electric Corporation. (2011). Overview of Plant Resource Manager (PRM). https://web-material3.yokogawa.com/TI_33Y05Q32-32E.pdf

\section{Web References}

https://www.ge.com/digital/sites/default/files/predix-platform-brief-ge-digital.pdf

https://www.neteon.net/media/downloads/Industrial_Protocols_Users_Guide_5e_7.pdf

https://www.nikhef.nl/pub/departments/ct/po/doc/CANopen30.pdf

https://www.yokogawa.com/in/solutions/products-platforms/solution-based-software/asset-management-softwar e/field-device-management-prm/

http://www2.emersonprocess.com/siteadmincenter/PM\%20Central\%20Web\%20Documents/Eng\%20Sch\%20-\% 20Buses\%20201.pdf

http://dl.mitsubishielectric.co.jp/dl/fa/document/catalog/plc/108111e/108111ef.pdf

http://people.cs.pitt.edu/ mhanna/Master/Introduction.pdf

http://www.modbus-ida.org

http://www.profibus.com/uploads/media/pxddamkey\%5B14067\%5D_Introduction $\% 20$ to\%20PROFIBUS $\% 20 \%$ 26\%20PROFINET.pdf

http://www8.cs.umu.se/education/examina/Rapporter/AdamAstrom.pdf

https://www.ge.com/digital/sites/default/files/Datasheet-Predix-Your-platform-for-the-Industrial-Internet.pdf

https://www.yokogawa.com/in/solutions/products-platforms/solution-based-software/asset-management-softwar e/field-device-management-prm/

https://www.ge.com/digital/sites/default/files/Datasheet-Predix-Your-platform-for-the-Industrial-Internet.pdf

\section{Copyrights}

Copyright for this article is retained by the author(s), with first publication rights granted to the journal.

This is an open-access article distributed under the terms and conditions of the Creative Commons Attribution license (http://creativecommons.org/licenses/by/4.0/). 